
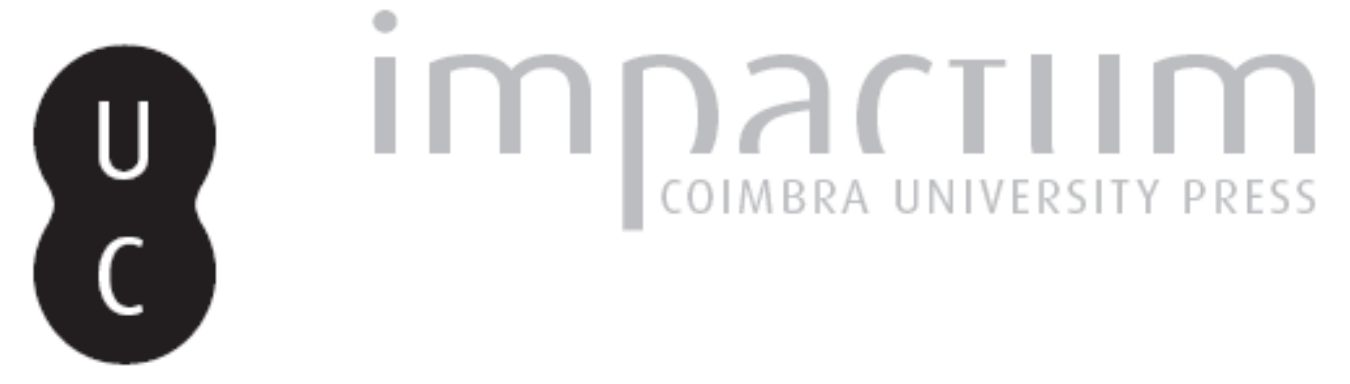

\title{
La violación como tópico en los Parallela Minora
}

Autor(es): Ibáñez Chacón, Álvaro

Publicado por: International Plutarch Society

URL persistente:

URI:http://hdl.handle.net/10316.2/36386

DOI:

DOI:http://dx.doi.org/10.14195/0258-655X_6_1

Accessed : $\quad$ 26-Apr-2023 11:44:19

A navegação consulta e descarregamento dos títulos inseridos nas Bibliotecas Digitais UC Digitalis, UC Pombalina e UC Impactum, pressupõem a aceitação plena e sem reservas dos Termos e Condições de Uso destas Bibliotecas Digitais, disponíveis em https://digitalis.uc.pt/pt-pt/termos.

Conforme exposto nos referidos Termos e Condições de Uso, o descarregamento de títulos de acesso restrito requer uma licença válida de autorização devendo o utilizador aceder ao(s) documento(s) a partir de um endereço de IP da instituição detentora da supramencionada licença.

Ao utilizador é apenas permitido o descarregamento para uso pessoal, pelo que o emprego do(s) título(s) descarregado(s) para outro fim, designadamente comercial, carece de autorização do respetivo autor ou editor da obra.

Na medida em que todas as obras da UC Digitalis se encontram protegidas pelo Código do Direito de Autor e Direitos Conexos e demais legislação aplicável, toda a cópia, parcial ou total, deste documento, nos casos em que é legalmente admitida, deverá conter ou fazer-se acompanhar por este aviso.

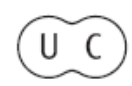




\section{PLOUTARCHOS, n.s.}

Scholarly Journal o

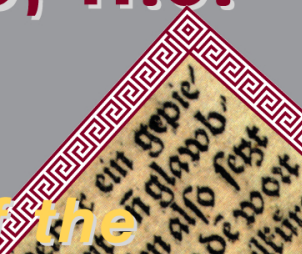

INTERNATIONAL PLUT A N NOS

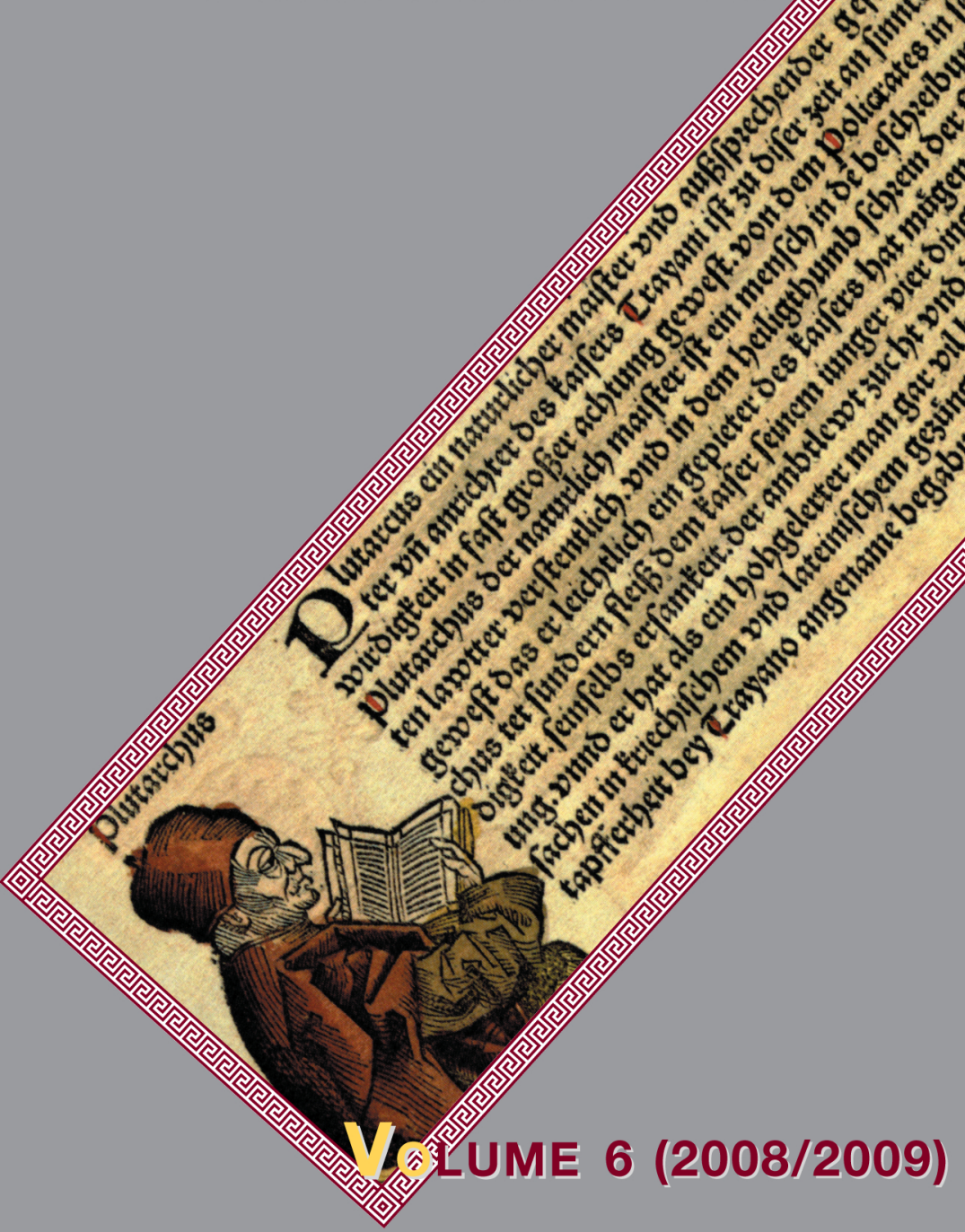

UNIVERSITY of Málaga (SPAin)

Utah State UniVersity, Logan, Utah (U.S.A.) 


\title{
La violación como tópico en los Parallela Minora por \\ Álvaro Ibáñez Chacón \\ IES Ilíberis, Atarfe (Granada) \\ alvaroich@yahoo.es
}

\begin{abstract}
The presence of erotic topics in the ps.-Plutarch's Parallela minora is abundant. In this case we briefly commented relative to the violation like the

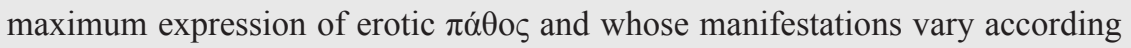
to the human or divine nature of the rapists, to the relations of kinship with the violated women (mainly incestuous violations) and to episodes metaphorically expressed by the recurrent kidnappings of virgins.

KEY-Words: Ps.-Plutarch, Parallela minora, Erotic Topics, Rape, Mythology.
\end{abstract}

una serie de tópicos que, en su recurrencia

I. Desde los poemas homéricos, la literatura griega siempre estuvo abierta al artística - principalmente literaria, pero también figurada-, se fueron modificando tratamiento más diverso y heterogéneo de de cada época ${ }^{2}$. En este lógico proceso, el las relaciones amorosas ${ }^{1} \mathrm{y}$, como en otras trágico Eurípides es un punto de inflexión muchas ocasiones, la civilización helena y referencia obligada, no sólo por sus sistematizó las expresiones eróticas en novelescas tramas tardías ${ }^{3}$, sino también

1 Véanse al respecto A. A. V. V., El descubrimiento del amor en Grecia, Madrid, 1985 y F. RodríGuez Adrados, Sociedad, amor y poesía en la Grecia antigua, Madrid, 1996.

2 En Calame, 2002 el lector podrá hallar excelentes referencias a tópicos, sociología, simbología y función de lo erótico.

3 J. L. CALVo, "El otro Eurípides: melodramas y tragicomedias", Flor. Il., 14 (2003) 35-51. 
por las grandes tragedias en las que el tipo especial de recopilación en prosa amor elevado a su máxima expresión de carácter mitográfico cuyo máximo produce las más grandes catástrofes ${ }^{4}$. exponente es Partenio de Nicea y su

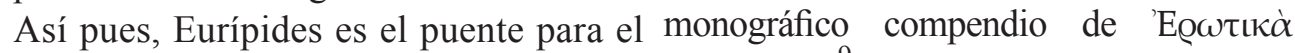
helenismo de un gran número de tópicos $\pi \alpha \theta \eta \dot{\mu} \mu \alpha \alpha^{9}$ con temas tratados por los eróticos que desembocarán, según las poetas y que se repiten -o bien sirvieron necesidades de cada género, en tramas de fuente- en la poesía latina y en otros de comedia ${ }^{5}$, argumentos de novela ${ }^{6}$ compendios como las Narraciones de o heterogéneas narraciones, todos los cuales se aglutinan, en cierta medida, en un amplio corpus de obras en las que es Eros protagonista ${ }^{7}$, sin olvidar, por supuesto, que la poesía es un vehículo privilegiado para la expresión erótica ${ }^{8}$.

Acercándonos más al tema que dos tratados de cuestionable autoría, el De nos ocupa, en el helenismo triunfó un fluuiis $^{11}$ y los conocidos como Parallela

4 F. Rodríguez Adrados, "Las tragedias eróticas de Eurípides”, ROcc, 107 (1990) 5-32.

5 Vid. L. GiL, "Comedia ática y sociedad ateniense I", EClás, 71 (1974) 60-82.

6 Vid. C. Miralles, La novela en la antigüedad clásica, Barcelona, 1968, pp. 55-61; C. García Gual, Los orígenes de la novela, Madrid, 1972, pp. 97-116.

7 Véase la recopilación y comentario de un buen elenco de prosa erótica A. STRAmaglia, (ed.), 'EQws. Antiche trame greche d'amore, Bari, 2000, así como la síntesis de M. Martínez Hernández, "Los géneros eróticos en la literatura griega", en Actas de X Congreso Español de Estudios Clásicos, Madrid, 2000, vol. I, pp. 497-504.

8 G. Giangrande, "La concepción del amor en Apolonio Rodio", en J. A. López Férez (ed.), La épica griega y su influencia en la literatura española, Madrid, 1993, pp. 213-233; Calderón Dorda, 1997b; Calame, 2002, pp. 70-78.

El más completo estudio de la obra mitográfica de Partenio es el de J. L. Lightfoot, Parthenius of Nicaea. The Poetical Fragments and the Erotika pathemata, Oxford, 1999, pp. 215-302; sobre su puesto en el corpus mythographicum vid. E. Pellizer, "La mitografia", en G. CAMBiAno, L. CANFora \& D. LANZA (eds.), Lo spazio letterario della Grecia antica, Roma, 1993, vol. I. 2, pp. 283-303; M. Alganza Roldín, "La mitografía como género de la prosa helenística: cuestiones previas", Flor. Il., 17 (2006) 9-37.

10 Vid. G. Giangrande, Plutarco. Narrazioni d'amore, Napoli, 1991, pp. 7-21; M. Valverde

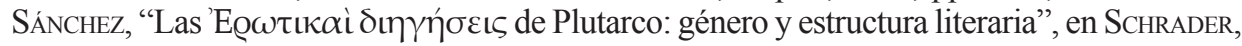
Ramón \& Vela (eds.), 1997, pp. 467-475; C. A. M. Jesus, "Eros e Thanatos nas Amatoriae Narrationes de Pseudo-Plutarco”, en Nieto IbÁÑEz \& LóPez LóPeZ, 2007, pp. 397-407.

11 Calderón Dorda, 1997a; Calderón Dorda, De Lazzer, \& Pellizer, 2003. 
minora, al que dedicamos este trabajo ${ }^{12}$. Más concretamente al estudio de una de las expresiones más patéticas de las relaciones amorosas: la excesiva pasión que lleva a la violación, un tema, sin duda, estandarizado y convertido en tópico literario.

II. La primera historia que contiene este tipo de tópos erótico es Par. min. 9B, en cuyo $m s$. $Ф \Pi$ se lee concretamente:

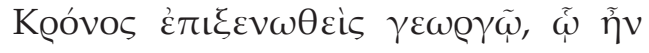

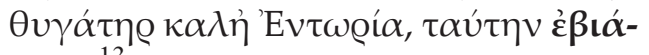
$\sigma \alpha \tau{ }^{13}$. Tenemos, por tanto, el tema de la violación ${ }^{14}$, marcada con el verbo $\beta$ tó́ $\omega$ (aunque también será recurrente parte, un gran número de historias hablan $\varphi \theta \varepsilon$ ć( $\omega)$, pero expresando la acción de reyes que hospedan a héroes y les en su aspecto más violento lejos de entregan a sus hijas, reyes que en su día cualquier circunloquio eufemístico, de también fueron héroes pero que ahora connotación psicológica o de deshonra ${ }^{15}$ : viven custodiando a su descendencia de hecho en griego no hay un término que femenina a la espera de que les den un específicamente designe a la violación en heredero de alta alcurnia y quién mejor

12 De todas las narraciones paralelas hemos excluido el tema homoerótico de Par. min. 33, tratado por nosotros en "Una historia sin 'paralelo': sobre la pederastia en Parall. Min. 33”, en Nieto IbáÑez \& López López, 2007, pp. 477-484; al igual que la interesante relación zoofílica de Par. min. 29 estudiada en "Pseudo-Plutarco, Parallela minora 29: tradición, reinvención, erudición”, Minerva, 20 (2007) 65-74.

13 Seguimos en todo momento la edición de A. De Lazzer, 2000; hay una versión española de los Parallela a cargo de M. López SalvÁ, Plutarco. Obras morales y de costumbres V, Madrid, 1989.

14 Además de la violación tenemos el tópos de la belleza de Entoria, recurrente en la elegía y en la mitografía, de ahí su presencia también en el De fluuiis; vid. CALDERón Dorda, 1997a, p. 110; 1997b, p. 3.

15 Vid. Paradiso, 1995, p. 97.

16 Vid. HARRIS, 2005.

17 El uso del término hýbris implica un deshonor que debe ser penalizado, frente a otras muestras de violencia sexual cuyas soluciones se plantean sin punición alguna, cfr. HARRIS, 2005, pp. 63 ss.

18 Paradiso, 1995, pp. 99-101; Harris, 2005, pp. 53-54. 
que un celebrado héroe para hacerlo, sin laguna contuviera la violación de Erígone embargo, la historia suele complicarse y a la manera de 9B, aunque el resto de lo hay inesperadas y trágicas muertes ${ }^{19}$. narrado en el paralelo romano fuese una

En Par. min. 9B la categoría de los personajes es distinta (un dios y un agricultor) y en lugar de una entrega voluntaria se ha invertido el tópico hacia el más patético (la violación), pero el final trágico sí que es recogido con el asesinato de uno de los hijos, el suicidio de los otros tres y la epidemia $\left(\lambda \circ \mu_{\text {ó }}\right)^{20}$ enviada por Apolo.

No cabe duda de que la narr. 9B se ha tenido que "fabricar" 21 a través de la superposición de este tipo de tópicos y quizá de la propia narr. 9A: ó Te@ì

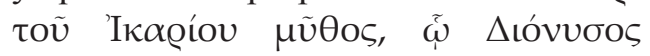

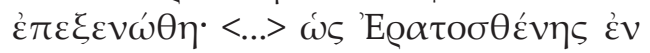
$\tau \tilde{\eta}$ 'Heı $\gamma$ óvฺ. Si el personaje de Entoria de 9B fue inventado sobre la base de Erígone en $9 \mathrm{~A}^{22}$, es probable que la mera invención. Sin embargo tenemos el problema de que ninguna fuente que narra el mito habla de que Dioniso violara a Erígone, a no ser que una breve alusión ovidiana así lo confirme: Liber ut Erigonem falsa deceperit una ${ }^{23}$.

El contexto de este hexámetro es el tapiz con el que Aracne rivalizó en destreza con la diosa Palas, un mito con múltiples lecturas pero que en referencia a los caelestia crimina -violaciones divinas- conlleva la existencia de alguna fuente anterior en la que la joven ateniense fue violada por el dios: en efecto, para unos el tapiz de la diosa Palas refleja mitos de maiestas olímpica y colores y formas relativas a Augusto, mientras que la obra de Aracne es una contrapartida de impietas en tanto que figura elementos

19 Vid. F. Létoublon, "Quand un roi reçoit un héros", en A. Montadori (dir.), Mythes et représentations de l'hospitalité, Paris, 1999, pp. 43-55.

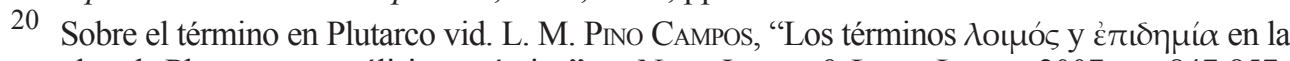
obra de Plutarco: un análisis semántico”, en NiETo IBÁÑEZ \& LóPEZ LóPEZ,, 2007, pp. 847-857.

21 Acerca del modus operandi del pseudo-Plutarco a la hora de fabricar las narraciones (griegas o romanas) paralelas partiendo de otras narraciones bien conocidas puede verse nuestro trabajo "Historia legendaria romana y sus 'paralelos' (Ps.-Plu. Par. min. 2 y 8)", CVDAS 5-6 (2004-2005) 29-43.

22 Opinión de G. KNAACK, "Entoria”, RE 5.2, (1905) col. 2650. La fuente sería, como se atestigua en el texto, el célebre poema de Eratóstenes, sobre el cual véanse E. MAAss, Analecta Eratosthenica, Berlin, 1883, pp. 59-138; F. Solmsen, "Eratosthenes' Erigone", TAPhA 78 (1947), 252-275; R. Merkelbach, "Die Erigone des Eratosthenes", en Miscellanea di Studi Alessandrini in memoria di Augusto Rostagni, Torino, 1963, pp. 469526 y algo más reciente A. RosokокI, Die Erigone des Eratosthenes: Eine kommentierte Ausgabe der Fragmente, Heidelberg, 1995. 
y motivos quizá antiaugústeos ${ }^{24}$, pero también hablan otros de una oposición en clave femenina del papel de la mujer como víctima frente a la masculina feminidad de la diosa uirago ${ }^{25}$, e incluso hay quienes plantean ciertos tipos de reivindicaciones morales y en contra del desmedido poder masculino de los Olímpicos ${ }^{26}$; si bien, a nuestro juicio, Ovidio ofrece un erudito catálogo de caelestia crimina relacionados con el sexo y puede que con su célebre ingenio el poeta retome el tema del vencedor vencido al presentar todas las fraudulentas formas que tienen que asumir los dioses para saciar sus deseos, es decir, el pretendido poder masculino quedaría sometido, finalmente, por la pasión amorosa; y a esa pasión habría sucumbido también Dioniso, aunque no conservemos la fuente ovidiana ${ }^{27}$.

(textualmente incluso) en Par. min. 26 y en la paradigmática leyenda de Rómulo y Remo en Par. min. 36.

En efecto, en Par. min. 26A sólo

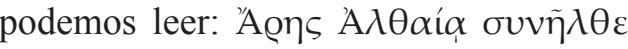

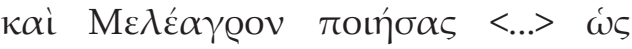

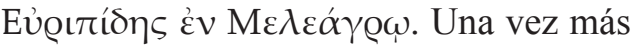
una laguna nos impide conocer si el autor sigue a la fuente citada para la historia griega en su paralelo romano ${ }^{28}$, donde el dios Marte con atuendo de pastor ( $\dot{\varepsilon} v$

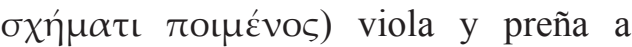

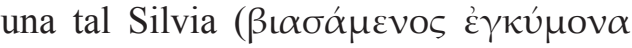

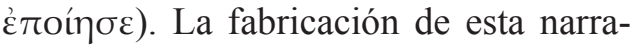
ción, al igual que la anterior, se ha hecho a partir de la aglutinación de tópicos y de historias conocidas: aprovechando al Ares del mito de Meleagro, el pseudo-Plutarco se inventa la historia de esta Silvia, en absoluto casualmente homónima a

Tenemos en esta historia, por tanto, el la Silvia madre de los fundadores de tema de la violación divina, que vuelve Roma $^{29}$. Así pues, mientras en el paralelo a aparecer de una forma muy similar romano se mantiene, por ejemplo ${ }^{30}$, el

L. C. CuRran, "Transformation and anti-Augustanism in Ovid's Metamorphoses", Arethusa, 5 (1972) 71-91; R. Di Fiore, "I colori di Aracne (Ovidio, Met. 6, 62-67), Aufidus, 35 (1998) 41-52; J. FABRe-SERRIs, Mythologie et littérature à Roma, Paris, 1998, pp. 46-49.

25 M. Von Albrecht, "L'épisode d'Arachné dans les Metamorphoses d'Ovide", REL, 57 (1979) 266-277.

26 Entre otros E. W. LEACH, "Ekphrasis and the Theme of Artistic Failulre in Ovid's Metamorphoses", Ramus, 3 (1974) 102-142; J.-P. NÉRAUdAU, "Les tapisseries de Minerve et d'Arachné (Ovide, Métamorphoses, VI, 70-128), L'Information littéraire, 35 (1983) 83-89; A. VIDEAU, "Le maître, le femme et l'éthique du savoir", Helmantica, 50 (1999) 769-780.

27 Como bien indica W. S. Anderson, Ovid's Metamorphoses books 6-10, Oklahoma, 1972, p. 167.

De LAZZer, 2000, p. 346, n. 222.

29 JACOBY, FGrHist IIIa, p. 399.

30 Pues la narración romana también se hace eco de la muerte del hijo a manos de la madre que lo controla y elimina atendiendo a lazos de sangre fraternales más que a su propia 
tema folclórico del "alma externada" paralelo romano. Sin embargo, debemos presente en la mayoría de los textos señalar que el pseudo-Plutarco elimina de clásicos $^{31}$ (aunque cambiando el tizón por esta historia la connotación violenta del una lanza), el motivo de la violación de hecho al utilizar expresiones eufemísticas

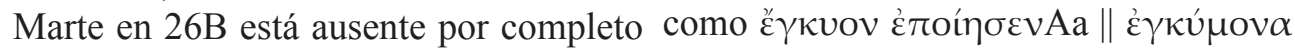

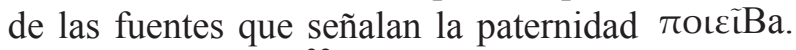

divina de Meleagro ${ }^{32}$.

En cambio, en Par. min. $36 \mathrm{Aa} / \mathrm{b}$ tenemos la técnica inversa: inventar el paralelo griego a través del celebérrimo mito de la concepción de Rómulo y Remo la manera del paralelo romano ${ }^{36}$ : $\Lambda$ oúkios

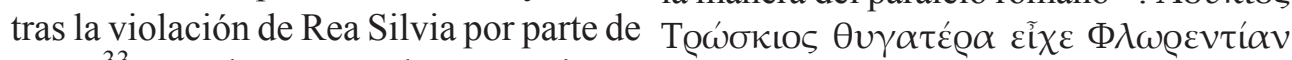

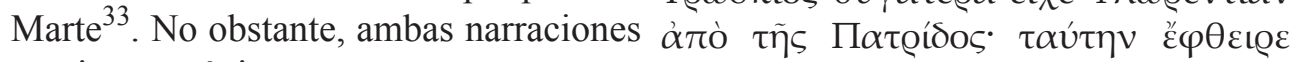

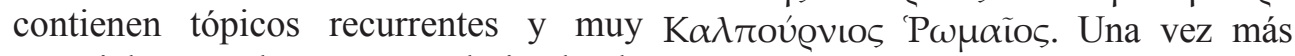
especialmente destaca uno derivado de la narración romana se ha fabricado la propia violación: el germen de esa utilizando los tópicos del paralelo griego unión violenta o ilícita es expuesto en y en este sentido podemos establecer una un lugar salvaje ${ }^{34}$, principalmente un misma secuencia para ambas narraciones: monte ${ }^{35}$, si bien el motivo tradicional de violación - exposición - venta - compra la exposición en el Tíber se respeta en el -legitimización.

relación filial, cfr. M. ALGANZA RoLDÁN, "Madres y madrastras en la tragedia y el mito griegos", en Mà. I. Sancho Rodríguez, L. Ruiz Solves \& F. Gutiérrez García (eds.), Lengua, Literatura y Mujer, Jaén, 2003, pp. 61-82, en concreto pp. 79-80.

31 Vid. A. Ruiz De Elvira, "Las grandes sagas heroicas y los cuentos populares", Jano 39 (1972) 49-51.

32 Por ejemplo Apollod. 1, 8, 2-3.

33 Cfr. De Lazzer, 2000, p. 358, n. 312. La bibliografía al respecto es muy abundante, pero en concreto sobre el mito y sus protagonistas véanse, entre otros, J. N. BREMMER, "Romulus, Remus and the foundation of Rome", en J. N. BRemmer \& N. M. Horsfall, Roman Myth and Mythography, London, 1987, pp. 25-48; A. LóPEz FonseCA, "Ilia/Rea Silvia. La leyenda de la madre del fundador de Roma", EClás 100 (1991) 43-54; T. P. Wiseman, Remus. Un mito di Roma, trad. it. Roma 1999.

En otras ocasiones los niños expósitos vienen "avalados" por cierto sueño premonitorio que la madre tiene durante el embarazo o bien por una orden oracular de Delfos, vid. E. Pellizer, La peripezia dell'eletto, Palermo, 1991, pp. 29-45. El motivo fue también ampliamente utilizado por Eurípides, véase M. Huys, The tale of Hero who was exposed at Birth in Euripidean Tragedy. A Study of Motifs, Leuven, 1995.

35 Vid. Buxton, 2000, pp. 94-95.

36 Sobre la corruptela y las variantes propuestas vid. De LAZZER, 2000, p. 348, n. 234. 
Como ya hemos señalado, de la la legitimización de la unión sexual a violación se desprende un sentimiento través del nacimiento de un hijo varón: de ultraje que obliga al padre a tras su peripecia amorosa, se establece el desembarazarse (en este caso) de la orden social de la mujer como madre. ultrajada: para ello se recurre a otro lugar tópico en el imaginario como es el mar, un espacio liminal entre dos mundos bien diferenciados ${ }^{37}$ y por tanto privilegiado

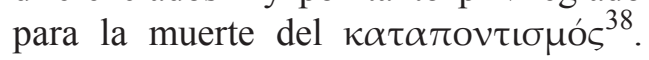
Pero también es un espacio dedicado al comercio, de ahí que la protagonista sea vendida en lugar de sacrificada, aunque en realidad se la sacrifica socialmente. De heroínas vendidas está el mito griego muy bien documentado y, aunque los estudiosos han destacado el hecho de que la novedad de nuestro texto radica en la venta final de la muchacha a su propio violador ${ }^{39}$, la verdad es que dicha novedad responde probablemente a las novelescas tramas de la comedia y en concreto al personaje de la "falsa hetera", cuya vivencia, desde sus primeras apariciones en la comedia vé $\alpha$ y la canonización del tipo en la comedia romana, se corresponde a su vez con una estructura típicamente euripidea: exposición - rapto - anagnórisis ${ }^{40}$. Así

La violación en este caso ha sido expresada por medio de $\varphi \theta \varepsilon i ́(\omega$, como también en Par. min. 13B (ФП) y $\sigma v \mu \varphi \theta \varepsilon i ́(\omega$ en $13 \mathrm{~B}(\Sigma)$, si bien la historia de una tal Clusia violada por Valerio Torcuato es otro puro invento a partir de su paralelo griego sobre Yole, pero como en $13 \mathrm{~A}$ no se habla de ningún tipo de ultraje.

IV. La violación de una doncella es un tema muy rico que puede aglutinar otros motivos eróticos tan recurrentes como el incesto, el cual establece a su vez otras estructuras bien definidas por medio de las cuales se desarrollan las narraciones. En los Parallela minora tenemos dos historias de violaciones incestuosas: Par. $\min .19$ A/B y Par. min. 28A, de las que analizaremos ahora sólo el tema de la violación, ya que el amor incestuoso merece un estudio aparte.

Así pues, en Par. min. 19A/B tenemos pues, con la compra de la mujer se produce una historia única no atestiguada en

37

38 Vid. C. Gallini, "Katapontismós”, SMSR 34 (1963) 61-90; A. De Lazzer, Il suicidio delle vergini. Tra folclore e letteratura della Grecia antica, Torino, 1997, pp. 86-109.

39 JACOBY, FGrHist IIIa, p. 372; De LAZZER, 2000, p. 348, n. 235.

40 Véanse al respecto L. GIL, “Comedia ática y sociedad atenienses III. Los profesionales del amor en la comedia media y nueva", EClás 73 (1975) 59-88: L. PÉRez Gómez, "Roles sexuales y conflictos de sexo en la comedia de Plauto", en A. López, C. MARTínez \& A. PociÑa (eds.), La mujer en el mundo mediterráneo antiguo, Granada, 1990, pp. 137-167; F. Souto Delibes, "El rol de la prostituta en la comedia: de Ferécrates a Menandro", $C F C$ : egi 12 (2002) 173-191. 
ningún otro texto grecolatino ${ }^{41}$, aunque líquido ${ }^{44}$.

está construida a partir de tópicos que hacen de ella un ejemplo típico de $\dot{\varrho} \omega \tau \tau$ เòv $\pi \dot{\alpha} \theta \eta \mu \alpha^{42}$. En efecto, remonta la causa de la violación (también expresada con $\beta \iota \alpha ́(\omega)$ a la borrachera enviada por Dioniso al no haber sido honrado en el sacrificio. Es muy significativo que en 19B se especifique que la deshonra divina se deba a la no ingestión de vino como una señal de desprecio del poder divino: Apvoútıs

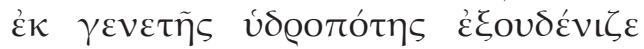

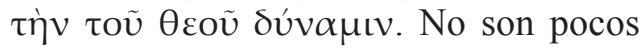
los mitos en los que Dioniso castiga a quienes desdeñan su poder e incluso su propia divinidad (Licurgo, las Miníades, Penteo...) y en este caso la versión de 19B matiza la etiología del castigo puntualizando que tan negativa es para el hombre la abstemia cuanto lo puede llegar a ser la embriaguez; repitiéndose por tanto la célebre ambigüedad de lo dionisíaco y del vino que Plutarco recoge en toda su obra ${ }^{43}$, así como el concepto de moderación en el uso simposíaco, ritual e incluso terapéutico del preciado

El patetismo de la historia radica una vez más en el castigo de la persona que ha cometido la falta y en ambos paralelos el padre es asesinado por su propia hija, si bien la trama de 19A es algo más novelesca que 19B: el castigo viene aconsejado desde Delfos y dirigido directamente " $a$ l impio" ( $\operatorname{còv} \dot{\alpha} \sigma \varepsilon \beta \tilde{\eta})$, pero el sufrimiento de la violada la dirige también a su propia inmolación sobre el cadáver del padre. En cambio, en 19B la venganza no implica castigo para la ultrajada, sino simplemente el sacrificio de su violador: $\delta \alpha \kappa \varrho v ́ \sigma \alpha \sigma \alpha$

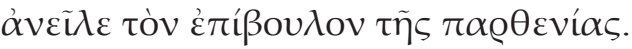
En ambas historias podemos ver también la impronta euripidea dejada en todos los géneros eróticos posteriores a sus dramas de reconocimiento por medio de objetos y nodrizas capitales para la resolución de la peripecia del héroe.

Otra violación incestuosa la hallamos en Par. min. 28, donde vemos en la versión griega el célebre mito de Cánace y Macareo, mientras que el

41 De Lazzer, 2000, p. 339, n. 167. No obstante, se olvida a menudo que Cándido María Trigueros compuso en el siglo XVIII una tragedia titulada Cíane de Siracusa o Las bacanales inspirada en esta narración pseudoplutarquea y mezclada con otras célebres tragedias griegas como el Edipo Rey de Sófocles, vid. C. T. PABón, "D. Cándido María Trigueros y su tragedia inédita Cíane de Siracusa", EClás 66 (1972) 229-245.

42 Según JACoBY, FGrHist IIIa, pp. 394-395 derivaría de Par. min. 21Aa: la historia de Cianipo y Léucone.

43 Vid. E. Suárez de la Torre, "Dioniso y el dionisismo en Plutarco", en Montes Cala, Sánchez Ortiz de Landaluce \& Gallé Cejudo (eds.), 1999, pp. 29-55.

44 Véanse la mayoría de trabajos incluidos en Montes Cala, SÁnchez Ortiz de Landaluce \& Gallé Cejudo (eds.), 1999, especialmente los de S.-T. Teodorsson, C. Alcalde Martín, E. Calderón Dorda, J. Capriglione, A. G. Nikolaidis y L. Van der Stockt. 
paralelo romano parece de nuevo una por parte de Idas y el paralelo romano historia totalmente inventada a partir ofrece de nuevo una invención a partir de las secuencias narrativas griegas. de las estructuras narrativas de la historia Centrándonos en la violación, de los anterior, pero con pequeñas diferencias. tres textos que De Lazzer edita para la versión griega, $28 \mathrm{Aa}(\varphi \mathrm{F} \Pi)$ y $28 \mathrm{Aa}(\Sigma)$ expresan la acción con $\tilde{\varepsilon} \varphi \theta \varepsilon$ เœ que $28 \mathrm{Ab}$ vuelve a recurrir a $\beta \mathrm{t} \alpha \omega \omega$; sin embargo, en el paralelo romano se utiliza una expresión eufemística: ह̌ $\gamma$ kvov

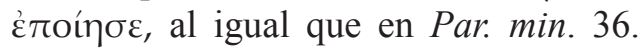
Pero resulta muy interesante que en los tres textos principales se "justifique" la violación por amor cuando en la mayoría de las fuentes es un erótico consenso entre los hermanos ${ }^{45}$, pero la hipótesis papirácea del Éolo euripideo confirma que la violación de Cánace era tratada por

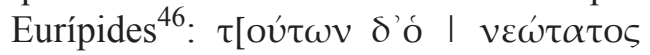

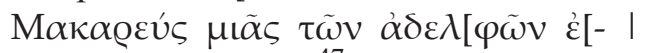

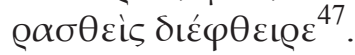

V. Metafóricamente, en Par. min. 40 que participan en algún rito o bien danzan se intuye una violación a través del tópico y juegan en floridos prados que preludian del rapto $^{48}$. En efecto, la versión griega una escena erótica tras la que se encubre cuenta el rapto de la virgen Marpesa el paso a la madurez sexual ${ }^{52}$. En este

45 Cfr. A. RuIz DE ElvirA, "Varia mythographa”, Emerita, 38 (1970) 291-310, especialmente pp. 301-308.

46 Vid. T. B. L. Webster, The Tragedias of Euripides, London, 1967, pp. 157-160; F. JouAN \& H. Van Looy, Euripide. Tragédies, tome VIII. 1, Paris, 2002, pp. 15-27.

47 Cfr. C. Austin, Nova Fragmenta Euripidea in Papyris Reperta, Berlin, 1968, p. 89.

48 Calame, 2002, pp. 80-82.

49 Calderón Dorda, 1997b, p. 4; M. P. PAtToni, "Innmoramiento nella Lesbo di Longo: topoi romanzeschi, reminiscenze epiche e saffiche memorie", Eikasmos, 15 (2004) 274303, pp. 273-284.

50 Sch. Hom. Il. 9, 557-558.

51 Ps.-Plu. De fluu. 8, 1.

52 Calame, 2002, pp. 160-163. 
sentido resulta muy interesante que en normas y la violación encubierta tras el

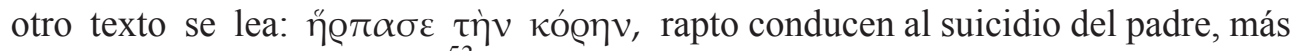

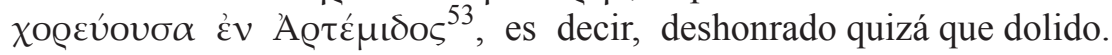
debemos entender que el rapto aconteció durante una celebración a la diosa del tránsito a la adultez $\mathrm{z}^{54} \mathrm{y}$ por tanto la deidad implicada,juntocon Heray Afrodita, en los avatares del matrimonio ${ }^{55}$. La inmadurez de la muchacha se marca también en el paralelo romano, donde en lugar de hablar de coros iniciáticos se nos dice que Cateto se enamoró de Salia cuando la vio mientras jugaba ( $\pi \alpha$ í $\zeta o v \sigma \alpha)$, luego no salimos de un estado infantil previo y muy significativo si tenemos en cuenta que a Ártemis ofrendaban las niñas sus muñecas y juguetes ${ }^{56}$.

El rapto supone una violación del normal desarrollo de los acontecimientos relativos al matrimonio y así, aparte de la custodia de la virginidad de la hija que recaía sobre el padre ${ }^{57}$, la persecución que en Par. min. 40A/B tiene su razón y la comedia nueva en novelle y novelas de de ser en que el matrimonio consistía en la época helenístico-imperial ${ }^{59}$, instalándose un consenso entre el padre y el futuro sin problemas en la producción literaria del esposo $^{58}$, de modo que obviar todas estas período conocido como Segunda Sofística.

53

54 Vid. J.-P. Vernant, La muerte en los ojos, trad. esp. Barcelona, 2001, pp. 24-29; P. Ellinger, "Ártemis”, en Bonnefoy, 2001², pp. 330-341.

55 M. Detienne, "Las divinidades del matrimonio", en Bonnefoy, 2001², pp. 139-150.

56 Detienne, cit. p. 142.

57 E. Pellizer, "Padri e figlie nell'immaginario della Grecia antica", en L. Accati, M. Cattaruzza \& M. Verzar Bass (eds.), Padre e figlia, Torino, 1994, pp. 77-94.

58 J.-P. Vernant, Mito y sociedad en la Grecia antigua, trad. esp. Barcelona, 1982, pp. 4668; J. Redfield, "Notes on the Greek wedding", Arethusa, 15 (1982) 181-201.

59

Vid. A. Ruiz de Elvira, "Mito y novella", CFC, 5 (1973) 15-52; V. CRISTÓBAL, "Tratamiento del mito en las novelle de las Metamorfosis de Apuleyo", CFC, 10 (1976) 309-373 y 
Bibliografía

BonNeFoy, I. (dir.),

- Diccionario de las mitologías, vol. 2: Grecia, trad. esp. Barcelona, 2001 ${ }^{2}$.

Buxton, R.,

- El imaginario griego. Los contextos de la mitología, trad. esp. Madrid, 2000.

Calame, C.,

- Eros en la antigua Grecia, trad. esp. Madrid, 2002.

CAlderón Dorda, E.,

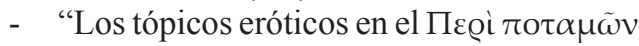
de Ps.Plutarco", in Schrader, RAmÓN \& VeLA, 1997a, pp. 109-115.

- "Los tópicos eróticos en la elegía helenística", Emerita, 65 (1997b) 1-15.

Calderón Dorda, E., De Lazzer, A. \& Pellizer, E,

- Plutarco. Fiumi e monti, Napoli, 2003.

De Lazzer, A.,

- Plutarco. Paralleli minori, Napoli, 2000.

HARris, E. M.

- "Did Rape exist in Classical Athens?", Dike, 7 (2005) 41-83.
Montes Cala, J. G., Sánchez Ortiz de Landaluce, M. \& Gallé Cejudo, R. J. (eds.),

- Plutarco, Dioniso y el vino. Actas del VI Simposio español sobre Plutarco, Cádiz, 14-16 de Mayo de 1998, Madrid, 1999.

Nieto IbÁÑEz, J. Mª \& López López, R. (eds.),

- El amor en Plutarco. Actas del IX Simposio Internacional de la Sociedad Española de Plutarquistas, León, 28-30 de septiembre de 2006, León, 2007.

Paradiso, A.,

- "Violenza sessuale, hybris e consenso nelle fonti greche", in Raffelli, R. (ed.), Vicente e figure femminili in Grecia e a Roma. Atti del Convengo di Pesaro, 28-30 Aprile, 1994, Ancona, 1995, pp. 93-109.

Schrader, C., Ramón, V. \& Vela, J. (eds.),

- Plutarco y la historia. Actas del V Simposio sobre Plutarco, Zaragoza, 20-22 de junio de 1996, Zaragoza, 1997.

VERnANT, J.-P.,

- Mito y sociedad en la Grecia antigua, trad. esp. Barcelona, 1982.

más recientemente L. Graverini, "Il romanzo greco", en L. Graverini, W. Keulen \& A. Barchiesi, Il Romanzo Antico. Forme, testi, problemi, Roma, 2006, pp. 75-130, en concreto pp. 47-53. 